\title{
The methodology of quantitative assess economic output of climate change
}

\author{
CHOU JieMing $^{1 *}$, DONG WenJie $^{1}$ \& FENG GuoLin ${ }^{2}$ \\ ${ }^{1}$ College of Global Change and Earth System Science, Beijing Normal University, Beijing 100857, China; \\ ${ }^{2}$ National Climate Center, China Meteorological Administration, Beijing 100081, China
}

Received November 22, 2010; accepted January 24, 2011

\begin{abstract}
A method is introduced in this paper to study the effect of future climatic change on the economy. The researchers determine the economic output of climate change from historical data, and provide a method to quantitatively predict economic output of climate change by an economic-climatic model. A historical reciprocating examination is used to analyze output data for various crops in eight agricultural areas in China and meteorological data from 160 observatories in China from 1980 to 2000 . The results show that the methods used are reasonable to a certain extent and good in application.
\end{abstract}

climate change, assessment, economic-climatic model, economic output

Citation: Chou J M, Dong W J, Feng G L. The methodology of quantitative assess economic output of climate change. Chinese Sci Bull, 2011, 56: 1333-1335, doi: $10.1007 / \mathrm{s} 11434-011-4429-8$

Enormous efforts have been made to simulate and predict regional responses to future climatic changes [1-3]. It is also necessary to assess quantitatively the impact of the changing information in these predictions on the social economy [4-7]. The "Yield Impact of Climate Change" (YICC) concept was introduced in the quantitative assessment of grain yield under the effects of climate change [8]. However, the YICC provides only a single index, which cannot show all the changes in economic output, and methods or indices to evaluate the impact of climate change on economic yield are scarce. This paper presents an economic modeling method to evaluate and predict the Economic Output Impact of Climate Change (EOICC) by making use of a derived "economic-climatic model" [9]. We validate the method using meteorological data from 160 observatories in China from 1981 to 2000, the total yield of grain, and the yield of other various crops across eight agricultural regions, and the results show that the predictions of the model are reasonable and effective in application.

The significance of this research is the introduction of

*Corresponding author (email: choujm@bnu.edu.cn) indices for evaluating the impact of climate change on economic output, which probes a new research area by incorporating economic factors into research on global climate change.

Supposing that the economic output to be evaluated complies with the "Cobb-Douglas" production function [10-12], great progress has been made on establishing and applying the economic-climatic model $[8,9,13]$. Taking grain output as an example, the following equation predicts the output by introducing climatic factors into the model:

$$
Y=x_{1}^{\beta_{1}} x_{2}^{\beta_{2}} x_{3}^{\beta_{3}} C^{\gamma} \mu=N_{c} C^{\gamma},
$$

where $Y$ is grain output, $N_{c}=x_{1}^{\beta 1} \cdots \mu$ is the contribution of non-climatic factors per unit area [9], $C$ is a climatic factor and $\gamma$ is the production elasticity of $C$ [9].

To predict EOICC for $n$ years in the future, we may assume that the means of $Y, N_{c}$ and $C$ in the past $n$ years are $Y_{1}, N_{c 1}$ and $C_{1}$, and the means in the next $n$ years are $Y_{2}, N_{c 2}$ and $C_{2}$ respectively, Then we have

$$
\begin{aligned}
& Y_{1}=N_{c 1} C_{1}^{\gamma}, \\
& Y_{2}=N_{c 2} C_{2}^{\gamma},
\end{aligned}
$$




$$
Y^{*}=N_{c 2} C_{1}^{\gamma},
$$

where $Y^{*}$ is the variation of economic output when $N_{c}$ is changed and $C$ is unchanged. The predicted EOICC, $\Delta Y$, is defined to be

$$
\Delta Y=Y_{2}-Y^{*}=Y_{2}\left(\frac{C_{2}^{\gamma}-C_{1}^{\gamma}}{C_{2}^{\gamma}}\right) .
$$

Equation (5) can be derived from

$$
\frac{\Delta Y}{Y_{2}}=\frac{C_{2}^{\gamma}-C_{1}^{\gamma}}{C_{2}^{\gamma}},
$$

where $\frac{\Delta Y}{Y_{2}}$ is the impact ratio of climate change on predicted economic output. This parameter can be used as an index to measure the impact of future climate change on economic output, and reflects the proportion of the future real output caused by climate change and the sensitivity of output to climate change.

As time progresses, the non-climatic factors in the model vary in accordance with the real situation, while grain yield per unit area is assumed to be constant when the climate is unchanged and no other real information is available. Little work has been done on extracting real-world information, and hence it is hard to verify the predicted EOICC value. In the following, we present a method that may overcome these difficulties.

Suppose $C$ is the impact factor of the climate change, and $\Delta C$ is the predicted change in $C$ at a given point in time in the future. We will continue with the example of grain yield.

Assume that mean grain yield, the effects of non-climatic factors, and the effects of climatic factors are given by $Y_{l}, k_{I}$ and $C_{l}$, respectively, during years 1 to $n$. Similarly the mean grain yield and the effects of non-climatic and climatic factors are characterized by $Y_{2}, k_{2}$ and $C_{2}$ during years $n+1$ to $2 n$. When $\Delta C$ is very small, the higher order polynomial terms can be ignored. That is,

$$
\begin{aligned}
& B=Y_{2}=F\left(C_{2}, k_{2}\right)=F\left(C_{1}+\Delta C, k_{2}\right) \\
& \approx F\left(C_{1}, k_{2}\right)+\frac{\partial F}{\partial C} \Delta C=A+\frac{\partial F}{\partial C} \cdot \Delta C,
\end{aligned}
$$

where $F$ is a function of $k$ and $C$, and $B$ is the grain yield for years $n+1$ to $2 n$ when social and climatic factors are considered. Note that $A=F\left(C_{1}, k_{2}\right)$, so $A$ is the grain yield when the social factors are quantified by $k_{2}$ and the climatic factor is unchanged. According to the definition of YICC,

$$
D=B-A=\frac{\partial F}{\partial C} \cdot \Delta C,
$$

where $D$ is the real EOICC to be estimated. Obviously, $B$ and $\triangle C$ can be obtained from historical data, so the EOICC calculation is simplified to estimating only $\frac{\partial F}{\partial C}$. However, when there is a sudden climatic change, the value of $\Delta C$ might be too large relative to the time scale to apply eq. (7).

Grain yield is a function of a social factor $k$ and a climatic factor $C$, and there is no correlation between $k$ and $C$. As we know, the inter-annual variation in the social factor is much less than the chronological variation. However, the inter-annual variation in the climatic factor is much larger than the chronological variation. Taking these two points into consideration, the method of composed analysis may be used to calculate $\frac{\partial F}{\partial C}$, where $\frac{\partial F}{\partial C}$ is the variability of various climate factors while the social factor $k$ is considered as unchanged.

Suppose that, as we would expect, the number of years in which the climatic factor is lower than its mean value of $C_{1}$ is equal to the number of years in which it is higher than the mean value. Assume that for the $n$ years with $C<C_{1}$, the mean value of the climatic factor is $C_{l}$, and for the $n$ years with $C>C_{1}$, the mean of the climatic factor is $C_{h}$. Statistically, the mean value of the social factor is just the mean over the $2 n$ years under consideration. Assuming the mean yield in years with $C<C_{1}$ is $Y_{l}$, and that the mean yield in the other years is $Y_{h}$. Then

$$
\frac{\partial F}{\partial C} \approx \frac{Y_{h}-Y_{l}}{C_{h}-C_{l}} .
$$

The non-climatic factors $A_{l}$ and $A_{h}$ are implicitly included when the time interval is divided into two groups in this way, and can be considered equal statistically.

Be applying the aforementioned method, the "real climatic change impacted amount" can be measured from existing information, which can be considered as the "real situation" for the purposes of validating the evaluation forecast.

Define $\frac{D}{\bar{Y}}$ as the impact ratio of climatic change, which reflects the real climatic change impacted amount as a proportion of the overall real yield. With this definition, the applicability of the proposed method can be validated by comparing the results of a simulation.

Eight agricultural regions (divided according to the division principle of Chinese agricultural regions) are selected, excluding Tibet, Taiwan and Inner Mongolia [14,15]. The precipitation and temperature data from 160 observatories are averaged in each of the eight regions during the growing season (April to September of 1980-2000). Using EOF expansion, the first principle element is chosen as the input parameter of climatic change, and the EOICC prediction methods for various kinds of crops are then examined. The economic data are sourced from "Year Book of Economic Statistics" and "Year Book of Agricultural Statistics", both published by China Statistics Press, and the climatic data from the database of the National Center for Climate of China. 
Comparing $\frac{D}{\bar{Y}}$ with $\frac{\Delta Y}{\bar{Y}}$ in Table 1 , it can be seen that the predicted wheat yield in five of the regions is quite accurate. It is within about $2 \%$ in Northeast and North China, 3\% in Central and East China, $8 \%$ in South China; and a little over 5\% in Southwest China. The differences are quite large in Northwest China and in Xinjiang.

For rice, the prediction is accurate in five regions, including Northeast $(1.86 \%)$, North (2\%), Central (about

Table 1 Comprehensive comparisons of $\frac{D}{\bar{Y}}$ and $\frac{\Delta Y}{\bar{Y}}$ in the eight regions

\begin{tabular}{|c|c|c|c|c|}
\hline \multicolumn{2}{|c|}{ Agricultural Regions } & \multirow{2}{*}{$\begin{array}{c}\text { Grain }(\%) \\
2.33\end{array}$} & \multirow{2}{*}{$\begin{array}{c}\text { Wheat }(\%) \\
2.36\end{array}$} & \multirow{2}{*}{$\begin{array}{c}\text { Rice }(\%) \\
1.86\end{array}$} \\
\hline Northeast & $\frac{D}{\bar{Y}}$ & & & \\
\hline China & $\frac{\Delta Y}{\bar{Y}}$ & 0.90 & 1.63 & 1.86 \\
\hline \multirow{2}{*}{$\begin{array}{l}\text { North } \\
\text { China }\end{array}$} & $\frac{D}{\bar{Y}}$ & 3.22 & 1.91 & 2.45 \\
\hline & $\frac{\Delta Y}{\bar{Y}}$ & 2.94 & 0.50 & 2.35 \\
\hline \multirow{2}{*}{$\begin{array}{c}\text { Central } \\
\text { China }\end{array}$} & $\frac{D}{\bar{v}}$ & 2.22 & 2.95 & -0.10 \\
\hline & $\frac{\Delta Y}{\bar{Y}}$ & 3.22 & 3.22 & 0.18 \\
\hline \multirow{2}{*}{$\begin{array}{c}\text { East } \\
\text { China }\end{array}$} & $\frac{D}{\bar{Y}}$ & 2.49 & 3.68 & 2.01 \\
\hline & $\frac{\Delta Y}{\bar{Y}}$ & 2.91 & 3.18 & 2.30 \\
\hline \multirow{2}{*}{$\begin{array}{l}\text { South } \\
\text { China }\end{array}$} & $\frac{D}{\bar{Y}}$ & 0.51 & 7.98 & 0.56 \\
\hline & $\frac{\Delta Y}{\bar{Y}}$ & 0.50 & 8.22 & 0.52 \\
\hline \multirow{2}{*}{$\begin{array}{c}\text { Southwest } \\
\text { China }\end{array}$} & $\frac{D}{\bar{Y}}$ & 4.38 & 5.07 & 3.61 \\
\hline & $\frac{\Delta Y}{\bar{Y}}$ & 8.76 & 5.94 & 7.10 \\
\hline \multirow{2}{*}{$\begin{array}{c}\text { Northwest } \\
\text { China }\end{array}$} & $\frac{D}{\bar{Y}}$ & 6.39 & 12.58 & 0.74 \\
\hline & $\frac{\Delta Y}{\bar{Y}}$ & 0.94 & 4.13 & 2.64 \\
\hline \multirow{2}{*}{ Xinjiang } & $\frac{D}{\bar{Y}}$ & 7.35 & 7.93 & 9.02 \\
\hline & $\frac{\Delta Y}{\bar{Y}}$ & 9.45 & 12.79 & 5.73 \\
\hline
\end{tabular}

$0.1 \%$ ), East (about 2\%) and South China (about 0.5\%), while it is less accurate in the Southwest, Northwest and Xinjiang regions.

For the total grain yield, it is accurate in the regions of North, Central, East and South China to within less than $1 \%$. The accuracy is between $1 \%$ and $2 \%$ in Northeast China, while in Southwest China, Northwest China and Xinjiang, the difference is greater than $2 \%$. The biggest difference is in Northwest China, where the value is larger than $5 \%$.

The difference between the value estimated based on real information and the predicted value from the model varies by region due to uncertainty in the model and the partial availability of real data.

An economic-climatic model and a prediction method for YICC are established to quantify the effect of climate change on future crop yield. The future YICC can be predicted by the model based on climatic data, solving the problem of the unavailability of social and economic data.

Also, we developed a method to assess the accuracy and reliability of the predicted EOICC. The validation was performed using data from eight agricultural regions across China. The results show that the model is applicable and presents meaningful conclusions. This evaluation method can be also applied for impact assessment in other industries using appropriate indices.

The main purpose of establishing an economic-climatic model and an economic method to predict EOICC is to estimate the effect of climate change on economic output under conditions of sustainable economic development. Although the method proposed in this paper may still be in its infancy, we have paved the way for future research and real applications.

\footnotetext{
The authors express their great thanks to Prof. Ye Duzheng, Institute of Atmospheric Physics, Chinese Academy of Sciences, for providing valuable guidance. This work was supported by the National Basic Research Program of China (2010CB950504) and the National High-Tech Research \& Development Program of China (2010AA12305).

1 Fu C B. Glob Planet Change, 2003, 37: 219-229

2 Ye D Z, Jiang Y D, Dong W J. Adv Atmos Sci, 2003, 20: 959-967

3 Gao X J, Zhao Z C, Giorgi F. Adv Atmos Sci, 2002, 19: 927-942

Ye D Z. Bull Chin Acad Sci, 1986, 1: 112-120

5 Ding Y H. Climate Change in China: Science, Influence, Adaption and Policy Research (in Chinese). Beijing: China Environmental Science Press, 2009. 1-455

6 Chou J M, Feng G L, Dong W J, et al. Clim Environ Res, 2004, 9: 597-603

7 Pan J H. World Econ Polic, 2003, 6: 66-71

8 Dong W J, Chou J M, Ye D Z. Adv Atmos Sci, 2007, 24: 336-342

9 Chou J M, Dong W J, Ye D Z. Chinese Sci Bull, 2007, 52: 1006-1008

10 Cobb C W, Douglas P H. Am Econ Rev, 1928, 18: 139-165

11 Solow R M. Quart J Econ, 1956, 70: 65-94

12 Solow R M. Econ Stat, 1957, 39: 312-320

13 Chou J M, Dong W J, Feng G L. Adv Atmos Sci, 2010, 27: 957-965

14 Climate Change and Crop Yield Writing Group. Climate Change and Crop Yield (in Chinese). Beijing: China Agriculture Technological Press, 1992. 1-2

15 Liu D M. J Chin Agr Resour Reg Plan, 2002, 23: 56-59
}

Open Access This article is distributed under the terms of the Creative Commons Attribution License which permits any use, distribution, and reproduction in any medium, provided the original author(s) and source are credited. 